Article

\title{
Hepatotoxicity, Nephrotoxicity and Oxidative Stress in Rat Testis Following Exposure to Haloxyfop-p-methyl Ester, an Aryloxyphenoxypropionate Herbicide
}

\author{
Ebenezer Tunde Olayinka * and Ayokanmi Ore \\ Biochemistry Unit, Department of Chemical Sciences, Ajayi Crowther University, PMB 1066, Oyo, \\ Oyo State 211213, Nigeria; E-Mail: oreayokanmi@gmail.com \\ * Author to whom correspondence should be addressed; \\ E-Mail: ebenezertundeolayinka@gmail.com; Tel.: +234-806-852-5502.
}

Academic Editor: Christos A. Damalas

Received: 10 August 2015 / Accepted: 9 October 2015 / Published: 15 October 2015

\begin{abstract}
Haloxyfop-p-methyl ester (HPME) ((R)-2-\{4-[3-chloro-5-(trifluoromethyl)-2pyridyloxy]phenoxy propionic acid), is a selective aryloxyphenoxypropionate (AOPP) herbicide. It exerts phytotoxicity through inhibition of lipid metabolism and induction of oxidative stress in susceptible plants. This study investigated the toxicological potentials of HPME in rats. Twenty-four male Wistar rats (170-210 g) were randomized into four groups (I-IV). Group I (control) received $1 \mathrm{~mL}$ of distilled water, while animals in Groups II, III and IV received $6.75,13.5$ and $27 \mathrm{mg} / \mathrm{kg}$ body weight HPME, respectively, for 21 days. There was a significant $(p<0.05)$ increase in renal and hepatic function biomarkers (urea, creatinine, total bilirubin, ALP, ALT, AST) in the plasma of treated animals compared to control. Levels of testicular antioxidants, ascorbic acid and glutathione, and activities of glutathione-S-transferase, superoxide dismutase and catalase were reduced significantly after 21 days of HPME administration in a dose-dependent manner. The testicular malondialdehyde level increased significantly in the HPME-treated rats relative to the control. A significant decrease in testicular lactate dehydrogenase, acid phosphatase and $\gamma$-glutamyl transferase was also observed in HPME-treated animals. Testicular histology revealed severe interstitial edema and sections of seminiferous tubules with necrotic and eroded germinal epithelium in the HPME-treated rats. Overall, data from this study suggest that HPME altered hepatic and renal function and induced oxidative stress and morphological changes in the testis of rats.
\end{abstract}


Keywords: aryloxyphenoxypropionate; haloxyfop-p-methyl ester; hepatotoxicity; nephrotoxicity; oxidative stress; testicular function; rat

\section{Introduction}

In the course of the last decade, applications of pesticides have increased steadily in Nigeria and in most developing countries as part of the effort to improve food production. Due to intensive applications, large amounts of these substances are released into the environment and find their way to non-target organisms, resulting in toxic effects [1]. Moreover, occupational exposure to these compounds may occur in agricultural workers, workers in the pesticide industry and retailers of the products from improper handling [2]. Some of the commonly-reported adverse effects of human and animal exposures to herbicides include oxidative stress, immunomodulation, disruption of reproductive functions [3] and histopathological alterations in vital organs [3].

Most of the widely-applied herbicides in Nigeria include the derivatives of aryloxyphenoxypropionates (AOPPs) [4], including haloxyfop-p-methyl ester (Figure 1). Haloxyfop-p-methyl ester (HPME) is employed for the control of broadleaf and grassy weeds in corn, sorghum, sugarcane, pineapple, Christmas trees and other crops. Although limited information exists on the metabolism of HPME in both plants and animals, haloxyfop- $p$ has been recovered as the major metabolite in plants and in soil [5]. The phytotoxicity mechanism of HPME involves inhibition of acetyl CoA carboxylase (an enzyme of lipid biosynthetic pathway) and induction of oxidative stress in susceptible plants species [6].

Although the mechanism of toxicity of HPME in animals is yet to be fully clarified, most of the reported toxicities of herbicides in mammals involved the generation of reactive oxygen species (ROS) or the disruption of redox balance in tissues [7]. Previously-studied AOPPs are known to generate free radicals and reactive oxygen species, leading to oxidative stress in susceptible plants and in non-target animal species $[8,9]$. There is increasing evidence suggesting that environmental contaminants play important roles in the modulation of tissue redox homeostasis [10]. Free radicals and reactive oxygen species (ROS) generated by these toxicants are highly reactive, and they can predispose the tissues to lipid peroxidation and tissue damages [11]. To maintain the physiological redox balance, enzymatic and non-enzymatic antioxidants are essential in defending tissues against the deleterious effects of ROS [12]. Generally, animal tissues possess the activities of enzymic antioxidants, like catalase (CAT), superoxide dismutase (SOD), glutathione peroxidase (GPx), etc., and non-enzymic antioxidants, like ascorbic acid (AA) and reduced glutathione (GSH). In addition, these antioxidants are also valuable indicators of oxidative damage and toxicities from environmental toxicants [13].



Figure 1. Haloxyfop-p-methyl ester methyl ((R)-2-\{4-[3-chloro-5-(trifluoromethyl)-2pyridyloxy]phenoxy propionate). 
Currently, little or no information exists on the acute and sub-acute toxicity of haloxyfop-p-methyl ester in non-target organisms, such as mammals. Considering the intensive application of this herbicide for domestic and agricultural purposes, an evaluation of its toxicological effects is of great importance for public health. Therefore, it was considered worthwhile to investigate the potential influence of haloxyfop- $p$-methyl ester on testicular function endpoints and the antioxidant defense mechanism in the testis of rats. In addition, renal and hepatic function parameters were also investigated following oral exposure to three different doses of the herbicide.

\section{Materials and Methods}

\subsection{Chemicals and Reagents}

Haloxyfop- $p$-methyl ester (Gallant Super ${ }^{\circledR}$ ) was purchased from Zhejiang Jinfanda Biochemical Co., Ltd., Zhejiang, China. Glutathione, 1-chloro-2,4-dinitrobenzene(CDNB), 5,5'-dithio-bis-2-nitrobenzoic acid (DTNB), epinephrine and hydrogen peroxide $\left(\mathrm{H}_{2} \mathrm{O}_{2}\right)$ were obtained from Sigma ${ }^{\circledR}$ Chemical Company, London, U.K. Assay kits for alanine aminotransferase (ALT), aspartate aminotransferase (AST), alkaline phosphatase (ALP), acid phosphatase (ACP), gamma glutamyl transferase ( $\gamma$-GT), urea, creatinine and bilirubin were products of RANDOX ${ }^{\circledR}$ Laboratories Ltd., Antrim, U.K. The assay kit for lactate dehydrogenase (LDH) was obtained from Cypress Diagnostics, Langdorp, Belgium. All other reagents employed were of analytical grade and highest purity.

\subsection{Animal Selection and Care}

Twenty-four male Wistar rats (170-210 g) were used in this study. They were acquired from the animal breeding unit, Department of Chemical Sciences, Ajayi Crowther University, Oyo, Nigeria. The animals were acclimatized to laboratory conditions for two weeks preceding the start of the study. The rats were contained in wire-meshed cages and provided with food and water ad libitum. They were kept at normal conditions of temperature and humidity and fed with commercial rat diet (Ladokun ${ }^{\circledR}$ Feeds, Nigeria Ltd., Ibadan, Nigeria). Handling of the experimental animals is consistent with international principles on the care and use of experimental animals [14].

\subsection{Experimental Design}

The animals were randomized into four experimental groups (I-IV) of six animals each. Animals in each group were treated as presented in Table 1. The respective doses were delivered in $1 \mathrm{~mL}$ solution, once daily by oral intubation, for a period of 21 days.

Table 1. Experimental design.

\begin{tabular}{cc}
\hline Treatment groups & Treatments \\
\hline I & Control \\
II & $6.75 \mathrm{mg} / \mathrm{kg} \mathrm{bw} \mathrm{HPME}$ \\
III & $13.5 \mathrm{mg} / \mathrm{kg} \mathrm{bw} \mathrm{HPME}$ \\
IV & $27.0 \mathrm{mg} / \mathrm{kg} \mathrm{bw} \mathrm{HPME}$ \\
\hline
\end{tabular}




\subsection{Collection of Blood and Testis}

Blood samples were obtained from each rat $24 \mathrm{~h}$ after the last treatment, through retro orbitals plexus. Blood samples were collected in heparinized ( $\mathrm{Li}$ heparin) sample tubes. Animals were thereafter euthanized, and testes were carefully removed from each animal for preparation of the testicular homogenates and histopathological analysis. Testicular samples meant for histopathological analysis were immediately fixed in Bouin's solution for $24 \mathrm{~h}$.

\subsection{Preparation of Plasma and Sub-Cellular Fractions of Testicular Homogenates}

Blood samples were centrifuged at $4000 \mathrm{rpm}$ for $5 \mathrm{~min}$ in a bench centrifuge (Analytika, Athens, Greece). Plasma obtained (the supernatant) was stored at $-4{ }^{\circ} \mathrm{C}$ for subsequent biochemical assays. Testis was rinsed in ice-cold $1.15 \% \mathrm{KCl}$ and homogenized in 4 volumes of ice-cold $0.01 \mathrm{M}$ potassium phosphate buffer ( $\mathrm{pH}$ 7.4). The homogenate was centrifuged at $12,500 \times g$ for $15 \mathrm{~min}$ at $-4{ }^{\circ} \mathrm{C}$ (Eppendorf, Stevenage, GB, U.K.), and the post-mitochondrial fraction (PMF) was used for subsequent biochemical assays.

\subsection{Assay of the Biomarkers of Hepatotoxicity}

Plasma total bilirubin and activities of alanine aminotransferase (ALT), alkaline phosphatase (ALP) and aspartate aminotransferase (AST) were assayed using RANDOX $^{\circledR}$ assay kits following the manufacturer's procedure. The procedure of Tietz [15] was followed in the determination of plasma TBILI level. The dimethyl sulfoxide formed is a colored compound absorbing maximally at $550 \mathrm{~nm}$. The activity of ALP was assayed following the principles of Tietz et al. [16] based on the hydrolysis of $p$-nitrophenyl phosphate to $p$-nitrophenol. The $p$-nitrophenol formed is yellow in color, and its intensity was observed at $405 \mathrm{~nm}$ to give a measure of ALP activity. Plasma ALT and AST activities were assayed by the method of Reltman and Frankel [17]. ALT activity was determined by observing the concentration of pyruvate hydrazone generated with 2,4-dinitrophenylhydrazine at a wavelength of $546 \mathrm{~nm}$. Plasma AST activity was determined by monitoring the concentration of oxaloacetate hydrazone produced with 2,4-dinitrophenylhydrazine at a wavelength of $546 \mathrm{~nm}$.

\subsection{Assay of the Biomarkers of Nephrotoxicity}

The levels of urea and creatinine in the plasma were assayed using RANDOX ${ }^{\circledR}$ assay kits following the manufacturer's protocol. The method for creatinine assays was done according to the colorimetric alkaline picrate method [15]. The creatinine-picrate complex formed has maximum absorbance at $492 \mathrm{~nm}$. Plasma urea concentration was assayed by the procedure of Jaffe [18], with a diazine chromogen generated absorbing maximally at a wavelength of $540 \mathrm{~nm}$.

\subsection{Assay of the Testicular Protein Content}

The protein content of the testicular PMF was assayed by the biuret procedure of Gornall et al. [19] using bovine serum albumin (BSA) as a standard protein. 


\subsection{Assay of the Biomarkers of Testicular Function}

Gamma glutamyl transferase ( $\gamma$-GT), acid phosphatase (ACP) and lactate dehydrogenase (LDH) were assayed in the testicular PMF using RANDOX ${ }^{\circledR}$ diagnostic kits according to the manufacturer's procedure. Testicular $\gamma$-GT activity was determined as described by Szasz [20]. ACP activity was determined by the method of Tietz [15] using $p$-nitrophenyl phosphate as the substrate. LDH activity was determined based on the method of Cabaud and Wroblewski [21].

\subsection{Assay of the Testicular Non-Enzymatic Antioxidants}

\subsubsection{Assay of the Testicular Glutathione Level}

The level of GSH in the testicular PMF was determined spectrophotometrically according to Jollow et al. [22]. The colored product (2-nitro-5-thiobenzoic acid) produced from the reaction of Ellman's reagent (5,5'-dithiobis-(2-nitrobenzoic acid), DTNB) with GSH has a molar absorption at $412 \mathrm{~nm}$.

\subsubsection{Assay of the Testicular Ascorbic Acid Level}

The ascorbic acid (AA) content was determined according to Jagota and Dani [23]. AA in biological samples reacts with Folin-Ciocalteu (Folin-phenol) reagent to give a blue color, which has maximum absorbance at $760 \mathrm{~nm}$.

\subsection{Assay of the Testicular Enzymic Antioxidants}

\subsubsection{Assay of the Testicular Glutathione- $S$-Transferase Activity}

The activity of GST in the testicular PMF was determined by the principle of Habig et al. [24] using 1-chloro-2,4-dinitrobenzene (CDNB) as the substrate.

\subsubsection{Assay of the Testicular Superoxide Dismutase Activity}

The activity of SOD in the testicular PMF was determined by the procedure of Misra and Fridovich [25]. This was achieved by monitoring the inhibition of auto-oxidation of epinephrine at alkaline $\mathrm{pH}(\mathrm{pH} 10.2)$.

\subsubsection{Assay of the Testicular Catalase Activity}

The activity of CAT in the testicular PMF was assayed by the method described by Singha [26]. Dichromate in acetic acid is reduced to chromic acetate when heated in the presence of $\mathrm{H}_{2} \mathrm{O}_{2}$. The chromic acetate formed was measured spectrophotometrically at the wavelength of $570 \mathrm{~nm}$. The activity of CAT in the sample was expressed as micromoles of $\mathrm{H}_{2} \mathrm{O}_{2}$ consumed per min per mg protein. 


\subsection{Assay of the Level of Lipid Peroxidation in the Testicular PMF}

The level of lipid peroxidation (LPO) in the testis was assayed by the method of Vashney and Kale [27]. Malondialdehyde (MDA; a product of lipid peroxidation) reacts with thiobarbituric acid to yield a pink chromogen, which absorbed maximally at $532 \mathrm{~nm}$.

\subsection{Testicular Histology}

The method described by Baker and Silverton [28] was employed in processing testicular samples for histopathological examinations. Bouin-fixed testicular tissues were dehydrated stepwise in graded ethanol and embedded in paraffin wax. A thin section (5- $\mu \mathrm{m}$ thickness) was made from the mid-portion of each sample and stained with hematoxylin and eosin, followed by examination under a light microscope.

\subsection{Statistical Analysis}

Data are presented as the mean \pm standard deviation (SD) of six replicates. Statistical significance was determined by one-way analysis of variance (ANOVA) and complemented with Duncan's multiple comparison between control and treated animals in all groups using SigmaPlot ${ }^{\circledR}$ statistical software (Systat ${ }^{\circledR}$ Software Inc., San Jose, CA, USA). $p$-values less than $0.05(p<0.05)$ were considered statistically significant.

\section{Results}

\subsection{Influence of Haloxyfop-p-methyl Ester on Hepatic Function Markers in the Plasma of Rat}

Data presented in Table 2 represent the hepatic function parameters of control and HPME-treated animals. Plasma bilirubin increased significantly $(p<0.05)$ in animals treated with HPME in a dose-dependent manner by $28 \%, 62 \%$ and $97 \%$, respectively. The activities of the marker enzymes ALP, ALT and AST also increased significantly in the plasma of HPME-treated animals compared to the control. The activity of ALP increased by $35 \%, 46 \%$ and $67 \%$, respectively, in the groups given 6.75 , 13.5 and $27 \mathrm{mg} / \mathrm{kg}$ bw HPME, respectively. The plasma activity of ALT also increased significantly by $18 \%, 35 \%$ and $49 \%$, respectively, in the HPME-treated animals compared to the control. In a similar manner, HPME caused a significant increase in plasma AST activity by $8 \%, 20 \%$ and $26 \%$, respectively, relative to the control.

Table 2. Effect of haloxyfop- $p$ methyl ester on plasma biomarkers of hepatic function in rat.

\begin{tabular}{ccccc}
\hline Treatment groups & Bilirubin (mg/dL) & ALP (U/L) & ALT (U/L) & AST (U/L) \\
\hline $0($ Control) & $0.29 \pm 0.01$ & $262.8 \pm 8.6$ & $30.4 \pm 3.1$ & $61.2 \pm 5.6$ \\
$6.75 \mathrm{mg} / \mathrm{kg} \mathrm{bw} \mathrm{HPME}$ & $0.37 \pm 0.01(28 \%) *$ & $355.4 \pm 9.1(35 \%) *$ & $36.0 \pm 2.6(18 \%) *$ & $66.4 \pm 4.1(8 \%) *$ \\
$13.50 \mathrm{mg} / \mathrm{kg} \mathrm{bw} \mathrm{HPME}$ & $0.47 \pm 0.02(62 \%) *$ & $384.2 \pm 6.6(46 \%) *$ & $41.1 \pm 2.3(35 \%) *$ & $73.4 \pm 5.1(20 \%) *$ \\
$27.00 \mathrm{mg} / \mathrm{kg}$ bw HPME & $0.57 \pm 0.01(97 \%) *$ & $438.8 \pm 7.4(67 \%) *$ & $45.2 \pm 3.6(49 \%) *$ & $77.0 \pm 2.7(26 \%) *$ \\
\hline
\end{tabular}

Values are the means \pm SD for six replicates; * values significantly different from the control at $p<0.05$; values in parenthesis represent the percentage $(\%)$ increase compared to the control. 


\subsection{Influence of Haloxyfop-p-methyl Ester on Renal Function Markers in the Plasma of Rat}

Data presented in Table 3 show the effect of different doses of HPME on the plasma level of urea and creatinine in rat. Plasma urea level increased significantly $(p<0.05)$ in the HPME-treated animals by $33 \%, 70 \%$ and $96 \%$, respectively, when compared to the control. Plasma creatinine also increased in a similar way by $33 \%, 57 \%$ and $73 \%$, respectively, in the treated groups relative to the control.

Table 3. Effect of haloxyfop- $p$ methyl ester on biomarkers of the renal function in rat.

\begin{tabular}{ccc}
\hline Treatment groups & Urea $(\mathbf{m g} / \mathbf{d L})$ & Creatinine $(\mathbf{m g} / \mathbf{d L})$ \\
\hline $0($ Control) & $18.0 \pm 2.3$ & $0.42 \pm 0.06$ \\
$6.75 \mathrm{mg} / \mathrm{kg} \mathrm{bw} \mathrm{HPME}$ & $24.1 \pm 1.8(33 \%)^{*}$ & $0.56 \pm 0.03(33 \%) *$ \\
$13.50 \mathrm{mg} / \mathrm{kg} \mathrm{bw} \mathrm{HPME}$ & $30.6 \pm 2.4(70 \%)^{*}$ & $0.66 \pm 0.03(57 \%) *$ \\
$27.00 \mathrm{mg} / \mathrm{kg}$ bw HPME & $35.3 \pm 3.1(96 \%) *$ & $0.73 \pm 0.07(73 \%) *$ \\
\hline
\end{tabular}

Values are the means \pm SD for six replicates; * values significantly different from the control at $p<0.05$; values in parenthesis represent the percentage (\%) increase compared to the control.

\subsection{Influence of Haloxyfop-p-methyl Ester on Biomarkers of Testicular Function in Rat}

The effect of HPME on testicular activities of acid phosphatase (ACP), lactate dehydrogenase (LDH) and $\gamma$-glutamyl transferase $(\gamma$-GT) are presented in Figure 2. Testicular $\gamma$-GT, ACP and LDH activities showed a significant $(p<0.05)$ decrease in all of the HPME-treated groups compared to the corresponding control values.

\subsection{Effect of Haloxyfop-p-methyl Ester on Biomarkers of Oxidative Stress in the Testis of Rat}

The effect of different doses of HPME on testicular biomarkers of oxidative stress is presented in Figure 3 (non-enzymic antioxidants), Figure 4 (level of lipid peroxidation) and Table 4 (enzymic antioxidants). A significant reduction in the testicular antioxidant status was noted, following exposure to HPME. The testicular levels of glutathione and ascorbic acid (the non-enzymic antioxidants) were significantly $(p<0.05)$ decreased in HPME-exposed rats in a dose-dependent manner compared to controls (Figure 3a,b). Testicular activities of the enzymic antioxidants GST, SOD and CAT were also significantly decreased in rats administered various doses of HPME (Table 4). GST activity decreased by $19 \%, 30 \%$ and $46 \%$ in the groups administered different doses of HPME. The activity of testicular SOD also decrease by $23 \%, 37 \%$ and $49 \%$ in the HPME-treated groups. Testicular CAT activity was significantly reduced by $24 \%, 44 \%$ and $60 \%$, respectively. HPME also caused a significant increase in the level of testicular malondialdehyde (MDA) level in the HPME-treated animals in a dose-dependent manner relative to the control (Figure 4). 
Table 4. Influence of haloxyfop- $p$-methyl ester on enzymatic antioxidants in the testis of rat.

\begin{tabular}{cccc}
\hline Treatment groups & GST (nM/min/mg protein) & SOD (units/mg protein) & $\begin{array}{c}\text { CAT }\left(\boldsymbol{\mu M} \mathbf{~}_{2} \mathbf{O}_{2}\right. \\
\text { consumed/min/mg protein) }\end{array}$ \\
\hline $0($ Control) & $22.6 \pm 1.7$ & $8.6 \pm 0.7$ & $13.9 \pm 1.2$ \\
$6.75 \mathrm{mg} / \mathrm{kg} \mathrm{bw} \mathrm{HPME}$ & $18.2 \pm 1.8(19 \%)^{*}$ & $6.6 \pm 0.5(23 \%) *$ & $10.6 \pm 0.7(24 \%)^{*}$ \\
$13.50 \mathrm{mg} / \mathrm{kg}$ bw HPME & $15.8 \pm 2.1(30 \%)^{*}$ & $5.4 \pm 0.6(37 \%)^{*}$ & $8.2 \pm 0.5(44 \%)^{*}$ \\
$27.00 \mathrm{mg} / \mathrm{kg}$ bw HPME & $12.1 \pm 1.5(46 \%) *$ & $4.4 \pm 0.4(49 \%) *$ & $6.1 \pm 0.5(60 \%) *$ \\
\hline
\end{tabular}

Values are the means $\pm \mathrm{SD}$ for six replicates; * values significantly different from the control at $p<0.05$; values in parenthesis represent the percentage (\%) decrease compared to the control.

\subsection{Effect of Haloxyfop-p-methyl Ester on Histological Characteristics of Rat Testis}

The representative photomicrographs of the testicular sections from rats in the control and HPME-treated groups are presented in Figure 5. Histopathological examination of testicular sections from rats in the control group demonstrated normal and well-defined cellular arrangements. However, exposure to $18.75 \mathrm{mg} / \mathrm{kg}$ bw HPME caused severe interstitial edema (OD) (Figure 5b). In addition, some sections of the seminiferous tubule displayed a necrotic and eroded germinal epithelium. In Figure 5c (37.50 mg/kg bw HPME), most sections of the seminiferous tubules have immature cells in the lumen (LM), and in Figure $5 \mathrm{~d}$ ( $75 \mathrm{mg} / \mathrm{kg}$ bw HPME), there are few cellular clumps in the lumen of some of the seminiferous tubules.
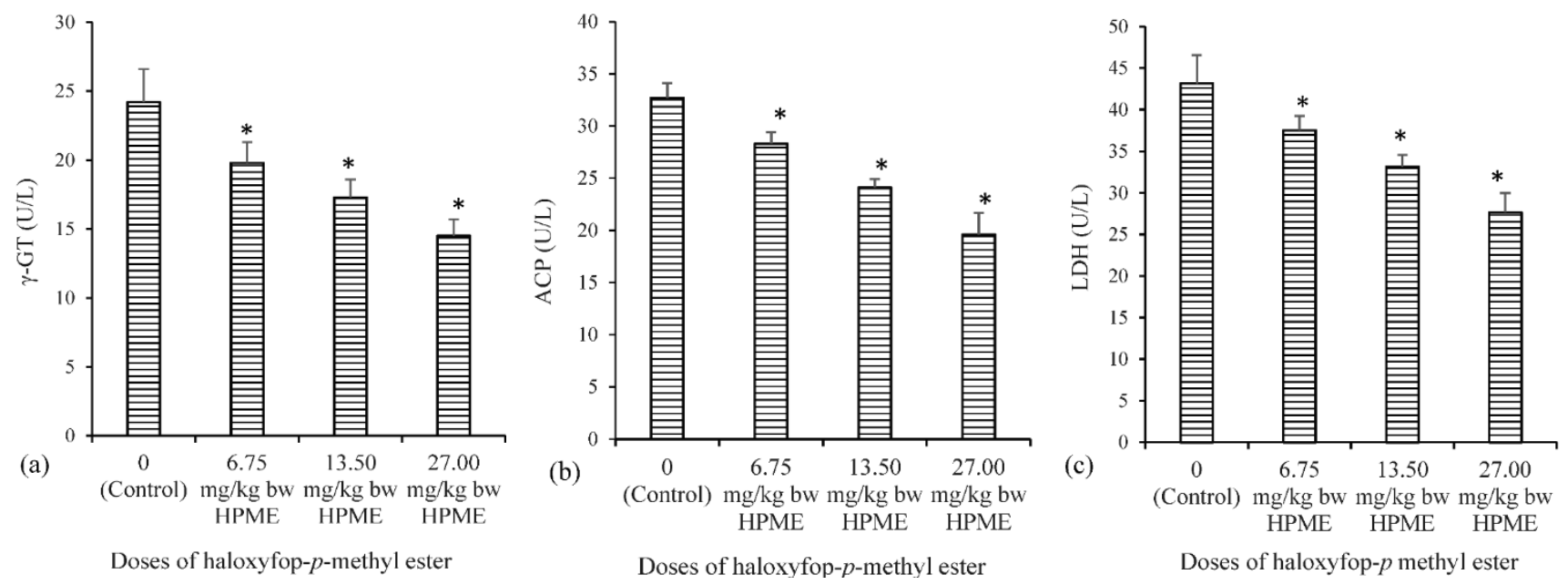

Figure 2. The influence of haloxyfop- $p$-methyl ester on biomarkers of testicular function in rat: (a) $\gamma$-glutamyl transferase $(\gamma-\mathrm{GT})$; (b) acid phosphatase (ACP); and (c) lactate dehydrogenase (LDH); data represent the mean of six replicates \pm standard deviation. * Significance of difference at $p<0.05$ (Duncan's multiple comparison of control and HPME-treated rats). 


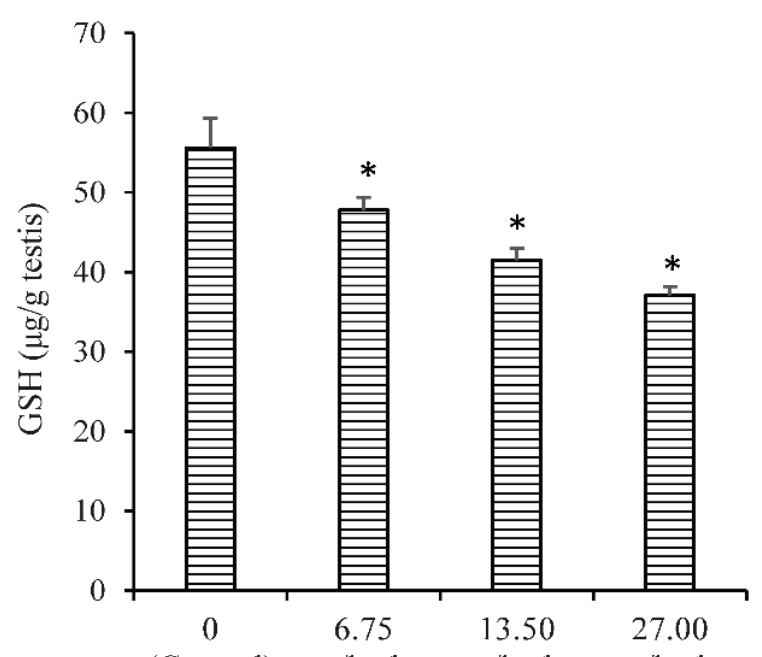

(a)
(Control) $\mathrm{mg} / \mathrm{kg} \mathrm{bw} \mathrm{mg} / \mathrm{kg} \mathrm{bw} \mathrm{mg} / \mathrm{kg} \mathrm{bw}$ HPME HPME HPME

Doses of haloxyfop- $p$ methyl ester

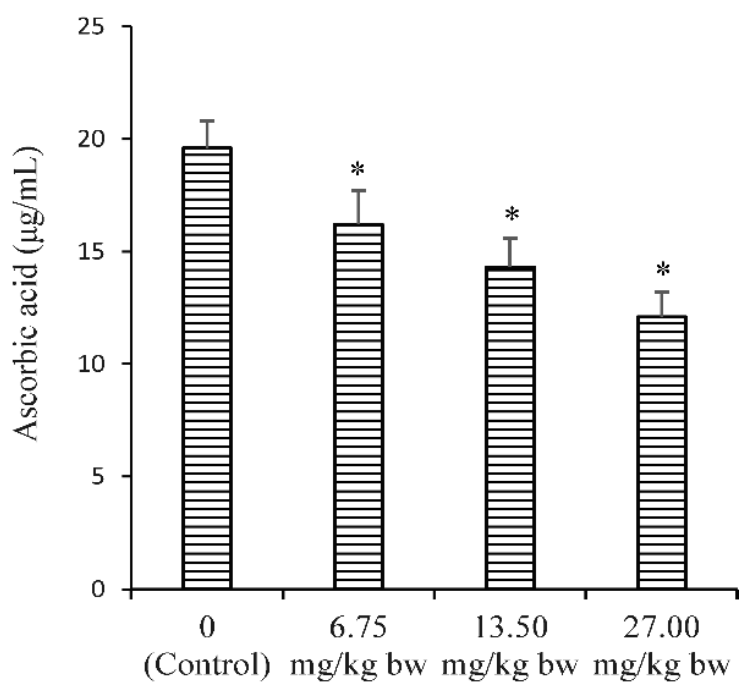

(b)

Doses of haloxyfop- $p$ methyl ester

Figure 3. The influence of haloxyfop-p-methyl ester on the levels of non-enzymatic antioxidants in rat testes: (a) reduced glutathione; and (b) ascorbic acid (AA); data represent the mean of six replicates \pm standard deviation. ${ }^{*}$ Significance of difference at $p<0.05$ (Duncan's multiple comparison of control and HPME-treated rats).

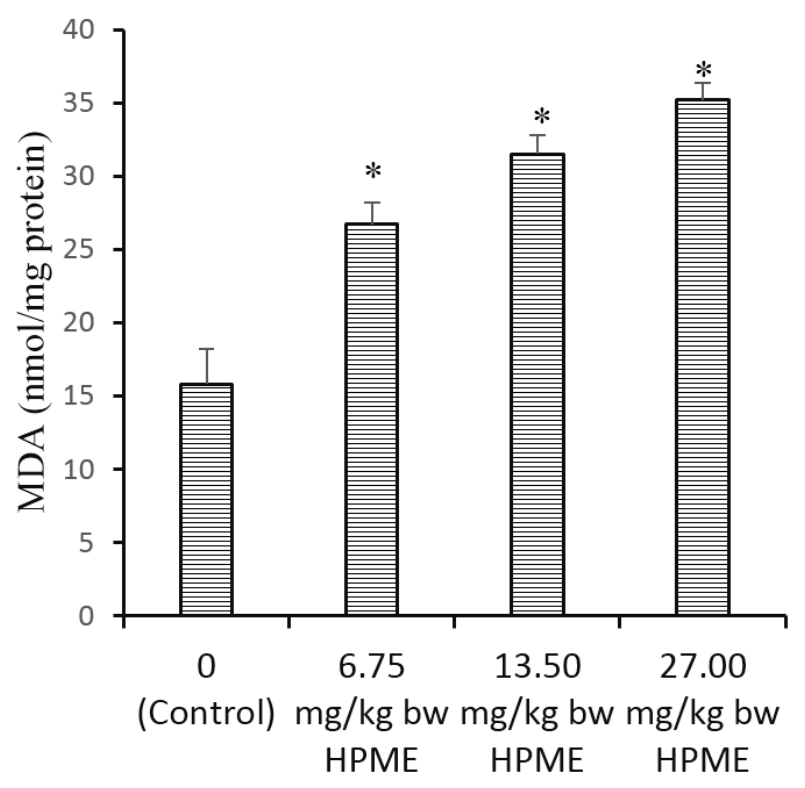

Doses of Haloxyfop-p-methyl ester

Figure 4. The influence of haloxyfop- $p$-methyl ester on the levels of malondialdehyde (MDA) in rat testis; data represent the mean of six replicates \pm standard deviation. * Significance of difference at $p<0.05$ (Duncan's multiple comparison of control and HPME-treated rats). 

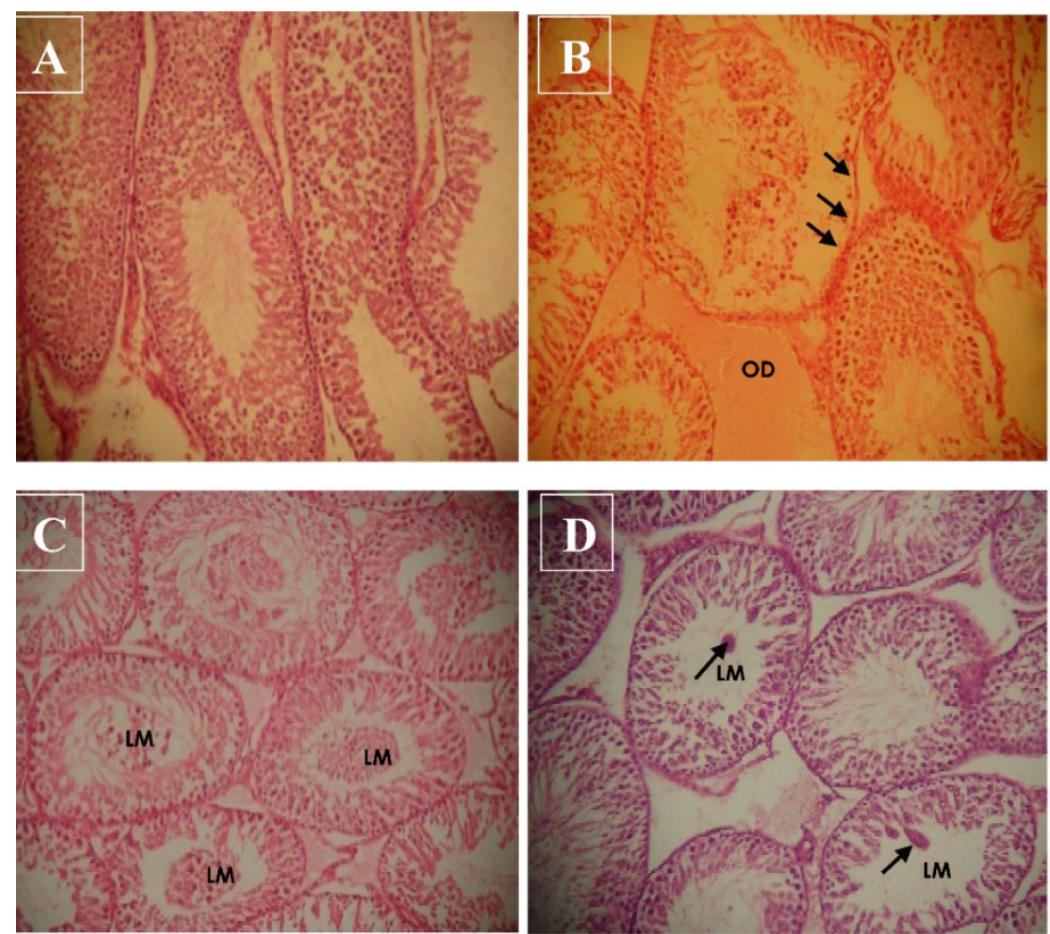

Figure 5. Representative photomicrograph of the testicular sections showing the morphological changes induced by haloxyfop- $p$-methyl ester in the testes of rats (hematoxylin and eosin stain, 200×); control group (A) and treated groups at the doses of $6.75 \mathrm{mg} / \mathrm{kg}$ bw (B), $13.50 \mathrm{mg} / \mathrm{kg}$ bw (C) and $27.00 \mathrm{mg} / \mathrm{kg}$ bw (D). (A) shows normal testicular structure; in (B), there are severe interstitial edemas (OD) and some sections of the seminiferous tubule have necrotic and eroded germinal epithelium; in (C), most sections of the seminiferous tubules have immature cells in the lumen (LM); and in (D), there are few cellular clumps in the lumen of some of the seminiferous tubules.

\section{Discussion}

The domestic, industrial and agricultural applications of herbicides have increased in the last decade, leading to better weed control and high economic gains in agriculture. Herbicides are developed, produced, packed and transported under strictly-regulated processes in order to minimize their impact on the environment and human health. Nevertheless, serious concerns have been raised about their potential public health risks from environmental contamination and occupational exposure [29]. Occupational exposure to herbicides may include the exposure of agricultural workers in farms and fields and workers in the pesticide industry, as well as retailers of the products [30]. The general population can also be exposed to residues of herbicides through food, contaminated water and domestic use. Exposure to these substances can result in a number of health effects depending on the toxicological properties of the substance involved, the concentration of the herbicide taken, the quantity applied in the environment, the half-life and the persistence of the active metabolites in the environment. Therefore, the assessment of the environmental and health effects of herbicides are very crucial for public health.

Most of the reported adverse effects of herbicides include organ toxicity, oxidative damage to tissues, endocrine disruptions and reproductive toxicities in human and animal studies [31]. The present study evaluates the potential effects of haloxyfop- $p$-methyl ester (HPME) on renal, hepatic and testicular 
functions in rat. The effects of the herbicide on biomarkers of oxidative stress were also considered in the testis of rat. Following oral exposure, toxicants are generally distributed and metabolized in the liver, which can predispose this organ to chemical-induced toxicity. The plasma level of total bilirubin and activities of the liver marker enzymes ALP, ALT and AST are well-established indices of hepatotoxicity [32]. An increase in the plasma level of total bilirubin (TBILI) and activity of ALP is associated with hepatobiliary damage and hepatic cholestasis [33]. Bilirubin is present in liver, bile, intestines and the reticuloendothelial cells of the spleen, while ALP is associated with the liver cell membrane [34]. The plasma TBILI level and activity of ALP are known to increase in conditions accompanying hepatobiliary damage and leakage of ALP from hepatocytes [35].

The presence of high plasma activities of ALT and AST is an established indicator of hepatocellular damage in human and animal studies [36]. Elevations of ALT and AST activities in the plasma has been linked to hepatocellular damages [37]. In this study, we observed a significant increase in plasma ALT and AST activities, suggesting their leakage from injured hepatocytes [38]. Previous studies have reported a similar increase in the plasma of herbicide-treated rat [39]. The present observation on HPME-induced increase in plasma TBILI and activities of liver markers (ALP, ALT and AST) is in agreement with previous work in our laboratory on the aryloxyphenoxypropionate herbicide fluazifop- $p$-butyl [9].

Plasma levels of urea and creatinine are important biomarkers of renal function in human and animal studies [40]. Data from this study indicate that HPME caused a significant increase in plasma urea and creatinine. An increase in the levels of these substances in the plasma is an indication of the loss of renal function [41]. Besides, earlier studies on phenoxypropionate herbicides observed a similar increase in plasma urea and creatinine [9].

The activities of $\gamma$-GT, ACP and LDH in testis are useful indices of testicular function and used in assessing testicular response to toxicants [42]. Testicular $\gamma$-GT activity is a useful indicator of Sertoli cell function [43]. $\gamma$-GT is involved in the metabolism of GSH, a process that delivers precursor amino acids for intracellular GSH synthesis [44]. A similar decrease in testicular $\gamma$-GT activity was also observed in an earlier study on fluazifop- $p$ butyl [9]. The activity of ACP is present in lysosomes of Leydig cells and is involved in the removal of unneeded sperm cells [45]. Moreover, the activity of testicular ACP may be used as an indicator of functional spermatogenesis [46]. Reduction in the activity of ACP in the testes of HPME-treated rats is an indication of testicular degeneration and a suppressed lysosomal function [47]. The activity of LDH in testis is associated with the maturation of the germinal epithelial layer of seminiferous tubule. It also plays a role in providing lactate to developing germ cells. LDH activity is also present in the Sertoli cells, where it participates in testicular energy metabolism [45]. The observed decrease in testicular LDH activity is an indication of the interference of HPME with testicular energy metabolism [48].

Industrial and environmental toxicants have been shown to possess the capacity to disrupt male fertility by inducing oxidative stress in the testes [49]. Normal testicular function is dependent on functional redox homeostasis regulated by the presence of enzymes, like SOD, CAT, GST, GPx, etc., and non-enzymic antioxidants, like AA, GSH, etc. [50]. The activities of these antioxidants are essential for redox balance and protection of spermatogenic cells, including the maintenance of overall male fertility [51]. The activity of SOD is vital to testicular defense strategy. The testes contain cytosolic $(\mathrm{Cu} / \mathrm{Zn}-\mathrm{SOD})$ and the mitochondrial (Fe/Mn-SOD), including the unusual extracellular SOD, (SOD-Ex), which is synthesized in the Sertoli and germ cells [52]. The activity of the testicular SOD 
system is required for the conversion of superoxide radical to hydrogen peroxide $\left(\mathrm{H}_{2} \mathrm{O}_{2}\right)$ and molecular oxygen [52]. The $\mathrm{H}_{2} \mathrm{O}_{2}$ generated in this process and other biochemical processes is transformed into water and oxygen through the action of CAT [53]. GST is a complex family of proteins that catalyze the conjugation of reduced glutathione to a wide variety of substrates in preparation for elimination from the cell [54]. GST activity is critical in the detoxification of peroxidized lipids, as well as the metabolism of toxicants [54]. However, GST also constitutes a vital component of the antioxidant system in the testis, and it has been reported to be essential for male fertility [55]. The observed pattern of HPME-induced depletion of the testicular enzymic antioxidant system is similar to that reported by Abarikwu et al. [56] on atrazine.

The non-enzymic antioxidant molecules, GSH and AA, play important roles in cellular redox balance. They function as free radical scavengers in cells and as the first line of antioxidant defense in tissues. GSH is a cofactor for glutathione peroxidase (GPx) and glutathione- $S$-transferase, and it also participates in free radical scavenging activities in the testis [57]. The decreased levels of GSH after exposure to HPME may be due to the consumption of GSH in the conjugation reaction or a decrease in its biosynthesis and turnover. AA functions in the aqueous environment and is involved in the preservation of tocopherol in cell membranes [53]. The decrease in levels of testicular GSH and AA observed in this study may be due to the presence of free radicals generated by HPME, thus predisposing the testis to oxidative stress [57].

The tissue level of MDA, an indicator of LPO, is a frequently-used marker of oxidative stress and tissue damage in vivo [50]. Despite the low oxygen tensions in the testicular micro-environment, this tissue remains vulnerable to oxidative stress due to the presence of unsaturated fatty acids [58]. LPO is a physiological event in normal cells and a well-known mechanism of cellular injury or stress response in animal tissues [59]. In previous studies, an increase in LPO has been observed as one of the testicular toxicity mechanisms induced by phenoxyacetic acid herbicides [60]. The fluidity of biological membranes is owed to the presence of polyunsaturated fatty acids (PUFAs) [61]. Since the testis is rich in PUFAs, it is easily prone to lipid peroxidation [50]. Peroxidation of membrane lipids can result in disruption of cell structural integrity [62] and cell damage. Hence, the increase in MDA levels caused by HPME in the rat testis suggests peroxidation of PUFAs in testicular cells, which can cause impairment of normal testicular and sperm function [63], which is common with phenoxyacetic acid herbicides [64].

In this study, HPME was found to induce various morphological degenerations in rat testis. The changes, which include severe interstitial edema (OD), necrotic and eroded germinal epithelium, the presence of immature germ cells and cellular clumps in the lumen of some of the seminiferous tubules, are similar to those obtained from studies on related AOPP (fluazifop- $p$-butyl) and other phenoxyacetic acid herbicides $[9,60]$.

\section{Conclusions}

Data from this study demonstrated that haloxyfop- $p$-methyl ester (at the doses tested) is capable of inducing testicular oxidative stress and causing impairment of renal and hepatic functions in rat. Oxidative stress plays a role in male fertility, and therefore, appropriate measures should be taken to minimize occupational exposure by applicators. Further studies are required to determine the toxicity of HPME in other non-target animal models, as well as in other tissues. 


\section{Author Contributions}

Both authors contributed to the study design, experimental works, data analysis and interpretation. The authors prepared, read and approved the final manuscript.

\section{Abbreviations}

\begin{tabular}{|c|c|}
\hline AOPPs & aryloxyphenoxypropionates \\
\hline HPME & haloxyfop- $p$-methyl ester \\
\hline CDNB & 1-chloro-2,4-dinitrobenzene \\
\hline DTNB & 5,5'-dithio-bis-2-nitrobenzoic acid \\
\hline bw & body weight \\
\hline PMF & post mitochondrial fraction \\
\hline BSA & bovine serum albumin \\
\hline $\mathrm{ddH}_{2} \mathrm{O}$ & double-distilled water \\
\hline TBILI & total bilirubin \\
\hline ALP & alkaline phosphatase \\
\hline $\mathrm{ACP}$ & acid phosphatase \\
\hline ALT & alanine aminotransferase \\
\hline AST & aspartate aminotransferase \\
\hline$\gamma$-GT & gamma glutamyl transferase \\
\hline LDH & lactate dehydrogenase \\
\hline SOD & superoxide dismutase \\
\hline CAT & catalase \\
\hline GPx & glutathione peroxidase \\
\hline GST & glutathione- $S$-transferase \\
\hline AA & ascorbic acid \\
\hline GSH & reduced glutathione \\
\hline LPO & lipid peroxidation \\
\hline MDA & malondialdehyde \\
\hline ROS & reactive oxygen species \\
\hline $\mathrm{H}_{2} \mathrm{O}_{2}$ & hydrogen peroxide \\
\hline PUFA & polyunsaturated fatty acids \\
\hline LM & lumen \\
\hline OD & edema \\
\hline
\end{tabular}

\section{Conflicts of Interest}

The authors declare that there is no conflict of interest. 


\section{References}

1. Hamilton, D.; Ambrus, A.; Dieterle, R.; Felsot, A.; Harris, C.; Petersen, B.; Racke, K.; Wong, S.S.; Gonzalez, R.; Tanaka, K.; et al. Pesticide residues in food-Acute dietary exposure. Pest. Manag. Sci. 2004, 60, 311-339.

2. Azmi, M.A.; Naqvi, S.N.; Azmi, M.A.; Aslam, M. Effect of pesticide residues on health and different enzyme levels in the blood of farm workers from Gadap (rural area) Karachi-Pakistan. Chemosphere 2006, 64, 1739-1744.

3. Mecdad, A.A.; Ahmed, M.H.; ElHalwagy, M.E.A.; Afify, M.M.M. A study on oxidative stress biomarkers and immunomodulatory effects of pesticides in pesticide-sprayers. Egypt. J. Forens. Sci. 2011, 1, 93-98.

4. Nestler, H.J. Phenoxy-Phenoxypropionic Acid Derivatives and Related Compounds; Chemie der P, S., Schädling-Sbekämp Fungsmittel, W.R., Eds.; Springer-Verlag: Berlin, Germany, 1982; pp. 1-25.

5. European Food Safety Authority. Reasoned opinion on the review of the existing maximum residue levels (MRLs) for haloxyfop-P. EFSA J. 2014, 12, 3861-3921.

6. Banaś, A.; Johansson, I.; Stenlid, G.; Stymne, S. Investigation of the mode of action of the herbicide haloxyfop. Zesz Nauk Wyższ Szk Roln P Siedlce Ser Nauki Przyrodnicze 1993, 34, 1-19.

7. Abdollahi, M.; Ranjbar, A.; Shadnia, S.; Nikfar, S.; Rezaiee, A. Pesticides and oxidative stress: A review. Med. Sci. Monit. 2004, 10, 144-147.

8. Luo, X.; Sunohara, Y.; Matsumoto, H. Fluazifop-butyl causes membrane peroxidation in the herbicide-susceptible broad leaf weed bristly starbur (Acanthospermum hispidum). Pest. Biochem. Physiol. 2004, 78, 93-102.

9. Ore, A.; Olayinka, E.T. Fluazifop-p-butyl, an Aryloxyphenoxypropionate Herbicide Diminishes Renal and Hepatic Functions and Triggered Testicular Oxidative Stress in Orally Exposed Rats Unpublished data, 2015.

10. Jasper, R.; Locatelli, G.O.; Pilati, C.; Locatelli, C. Evaluation of biochemical, hematological and oxidative parameters in mice exposed to the herbicide glyphosate-Roundup ${ }^{\circledR}$. Interdiscip. Toxicol. 2012, 5, 133-140.

11. Valko, M.; Leibfritz, D.; Moncola, J.; Cronin, M.T.D.; Mazura, M.; Telser, J. Free radicals and antioxidants in normal physiological functions and human disease. Int. J. Biochem. Cell Biol. 2007, $39,44-84$.

12. Vidyasagar, J.; Karunakar, N.; Reddy, M.S.; Rajnarayana, K.; Surender, T.; Krishna, D.R. Oxidative stress and antioxidant status in acute organophosphorous insecticide poisoning. Indian J. Pharmacol. 2005, 36, 76-79.

13. Valavanidisa, A.; Vlahogiannia, T.; Dassenakisb, M.; Scoullos, M. Molecular biomarkers of oxidative stress in aquatic organisms in relation to toxic environmental pollutants. Ecotoxicol. Environ. Saf. 2006, 64, 178-189.

14. National Research Council. Guide for the Care and Use of Laboratory Animals, 8th ed.; The National Academies Press: Washington, DC, USA, 2011.

15. Tietz, N.W. Clinical Guide to Laboratory Tests, 3rd ed.; W.B. Saunders Company: Philadelphia, PA, USA, 1995. 
16. Tietz, N.W.; Pruden, E.L.; Siggaard-Andersen, O. Liver Function. In Tietz Textbook of Clinical Chemistry; Burtis, A.C., Ashwood, E.R., Eds.; WB Saunders: London, UK, 1994; pp. 1354-1374.

17. Reltman, S.; Frankel, S.A. Colorimetric method for the determination of serum ALT and AST. Am. J. Clin. Pathol. 1957, 28, 56-63.

18. Jaffe, E.R. Oxidative Hemolysis, or What Made the Red Cell Break? N. Engl. J. Med. 1972, 286, 156-157.

19. Gornall, A.C.; Bardwawill, C.J.; David, M.M. Determination of serum protein by means of the biuret reaction. J. Biol. Chem. 1949, 177, 751-756.

20. Szasz, G. A kinetic photometric method for serum $\gamma$-glutamyl transpeptidase. Clin. Chem. 1969, 15, 124-136.

21. Cabaud, P.G.; Wroblewski, F. Colorimetric measurement of lactic dehydrogenase activity of body fluids. Am. J. Clin. Pathol. 1958, 30, 234-236.

22. Jollow, D.J.; Mitchell, J.R.; Zampaghone, N.; Gillete, J.R. Bromobenzene induced liver necrosis, protective role of glutathione and evidence for 3,4-bromobenzene oxide as the hepatotoxic metabolite. Pharmacology 1974, 11, 151-169.

23. Jagota, S.K.; Dani, H.M. A new colorimetric technique for the estimation of vitamin C using Folin phenol reagent. Anal. Biochem. 1982, 127, 178-182.

24. Habig, W.A.; Pabst, M.J.; Jacoby, W.B. Glutathione trsansferases. The first enzymatic step in mercapturic acid formation. J. Biol. Chem. 1974, 249, 7130-7139.

25. Misra, H.P.; Fridovich, I. The role of superoxide anion in the auto-oxidation of epinephrine and a simple assay for superoxide dismutase. J. Biol. Chem. 1972, 247, 3170-3175.

26. Singha, A.K. Colorimetric assay of catalase. Anal. Biochem. 1972, 47, 389-394.

27. Varshney, R.; Kale, R.K. Effect of calmodulin antagonist on radiation induced lipid peroxidation in microsomes. Int. J. Radiat. Biol. 1990, 58, 733-743.

28. Baker, F.J.; Silverton, R.E. Introduction to Medical Laboratory Technology, 6th ed.; Butter Worth: London, UK, 1985.

29. Maroni, M.; Fanetti, A.C.; Metruccio, F. Risk assessment and management of occupational exposure to pesticides in agriculture. Med. Lav. 2006, 97, 430-437.

30. Damalas, C.A.; Eleftherohorinos, I.G. Pesticide Exposure, Safety Issues, and Risk Assessment Indicators. Int. J. Environ. Res. Public Health 2011, 8, 1402-1419.

31. Gaikwad, A.S.; Karunamoorthy, P.; Kondhalkar, S.J.; Ambikapathy, M.; Beerappa, R. Assessment of hematological, biochemical effects and genotoxicity among pesticide sprayers in grape garden. J. Occup. Med. Toxicol. 2015, 10, 11-16.

32. Hauser, R.; Chen, Z.; Pothier, L; Ryan, L.; Altshul, L. The relationship between human semen parameters and environmental exposure to polychlorinated biphenyls and $p, p^{\prime}$-DDE. Environ Health Perspect. 2003, 111, 1505-1511.

33. Singh, A.; Bhat, T.K.; Sharma, O.P. Clinical Biochemistry of Hepatotoxicity. J. Clin. Toxicol. 2011, S4, 2-19.

34. Cullen, J.M. Mechanistic classification of liver injury. Toxicol. Pathol. 2005, 33, 6-8.

35. Ramaiah, S.K. A toxicologist guide to the diagnostic interpretation of hepatic biochemical parameters. Food Chem. Toxicol. 2007, 45, 1551-1557. 
36. Giannini, E.G.; Testa, R.; Savarino, V. Liver enzyme alteration: A guide for clinicians. CMAJ 2005, 172, 367-379.

37. Aly, N.; El-Gendy, K. Impact of parathion exposure on some biochemical parameters in rabbit as a non-target organism. Alexandria J. Med. 2015, 51, 11-17.

38. Amacher, D.E. Serum Transaminase Elevations as Indicators of Hepatic Injury Following the Administration of Drugs. Regul. Toxicol. Pharmacol. 1998, 27, 119-130.

39. Elefsiniotis, I.S.; Liatsos, G.D.; Stamelakis, D.; Moulakakis, A. Case Report: Mixed Cholestatic/Hepatocellular Liver Injury Induced by the Herbicide Quizalofop- $p$-ethyl. Environ. Health Perspect. 2007, 115, 1479-1481.

40. Ferguson, M.A.; Waikar, S.S. Established and Emerging Markers of Kidney Function. Clin. Chem. 2012, 58, 4-14.

41. George, G.S.; Wakasi, M.E.; Egoro, E. Creatinine and urea levels as critical markers in end-stage renal failure. Res. Rev. J. Med. Health Sci. 2014, 3, 41-44.

42. Hodgen, G.D.; Sherins, J.R. Enzymes as markers of testicular growth and development in the rat. Endocrinology 1973, 93, 985-989.

43. Sherins, R.J.; Hodgen, G.D. Testicular gamma glutamyl-transpeptidase: An index of Sertoli cell function in man. J. Reprod. Fertill. 1976, 48, 191-193.

44. Lushchak, V.I. Glutathione Homeostasis and Functions: Potential Targets for Medical Interventions. J. Amino Acids 2012, 2012, 1-26.

45. Rato, L.; Alves, M.G.; Socorro, S.; Duarte, A.I.; Cavaco, J.E.; Oliveira, P.F. Metabolic regulation is important for spermatogenesis. Nat. Rev. Urol. 2012, 9, 330-338.

46. Carreau, S.; Drosdowsky, M.A.; Foucault, P. Enzymatic properties of adult human Sertoli cells in vitro. Andrologia 1996, 28, 89-95.

47. Jana, K.; Jana, S.; Samanta, P.K. Effects of chronic exposure to sodium arsenite on hypothalamo-pituitary-testicular activities in adult rats: Possible an estrogenic mode of action. Reprod. Biol. Endocrinol. 2006, 4, 9-21.

48. Srivastava, S.; Sing, G.B.; Srivastava, S.P.; Seth, P.K. Testicular toxicity of di- $n$-butyl-phthalate in adult rats: Effect on marker enzymes of spermatogenesis. Ind. J. Exp. Biol. 1990, 28, 67-70.

49. Latchoumycandane, C.; Mathur, P.P. Induction of oxidative stress in the rat testis after short-term exposure to the organochlorine pesticide methoxychlor. Arch. Toxicol. 2002, 76, 692-698.

50. Aitken, R.J.; Roman, S.D. Antioxidant systems and oxidative stress in the testes. Oxid. Med. Cell. Longev. 2008, 1, 15-24.

51. Tremellen, K. Oxidative stress and male infertility-A clinical perspective. Hum. Reprod. Update 2008, 14, 243-258.

52. Mruk, D.D.; Silvestrini, B.; Mo, M.Y.; Cheng, C.Y. Antioxidant superoxide dismutase-A review: Its function, regulation in the testis, and role in male fertility. Contraception 2002, 65, 305-311.

53. Zini, A.; Schlegel, P.N. Catalase mRNA expression in the male rat reproductive tract. J. Androl. 1996, 17, 473-480.

54. Sheehan, D.; Meade, D.; Foley, V.M.; Dowd, C.A. Structure, function and evolution of glutathione transferases: Implications for classification of non-mammalian members of an ancient enzyme superfamily. Biochem. J. 2001, 360, 1-16. 
55. Aravinda, S.; Gopalakrishnan, B.; Dey, C.S.; Totey, S.M.; Pawshe, C.H.; Salunke, D.; Kaur, K.; Shaha, C. A Testicular Protein Important for Fertility Has Glutathione-S-Transferase Activity and Is Localized Extracellularly in the Seminiferous Tubules. J. Biol. Chem. 1995, 270, 15675-15685.

56. Abarikwu, S.O.; Adesiyan, A.C.; Oyeloja, T.O.; Oyeyemi, M.O.; Farombi, E.O. Changes in sperm characteristics and induction of oxidative stress in the testis and epididymis of experimental rats by a herbicide, atrazine. Arch. Environ. Contam. Toxicol. 2010, 58, 874-882.

57. Peltola, V.; Huhtaniemi, I.; Ahotupa, M. Antioxidant enzyme activity in the maturing rat testis. J. Androl. 1992, 13, 450-455.

58. Furland, N.E.; Zanetti, S.R.; Oresti, G.M.; Maldonado, E.N.; Aveldano, M.I. Ceramides and Sphingomyelins with High Proportions of Very Long-Chain Polyunsaturated Fatty Acids in Mammalian Germ Cells. J. Biol. Chem. 2007, 282, 18141-18150.

59. Mylonas, C.; Kouretas, D. Lipid peroxidation and tissue damage. In Vivo 1999, 13, 295-309.

60. Joshi, S.C.; Tibrewal, P.; Sharma, A.; Sharma, P. Evaluation of toxic effect of 2,4-D (2,4-dichlorophenoxyacetic acid) on fertility and biochemical parameters of male reproductive system of albino rats. Int. J. Pharm. Pharm. Sci. 2012, 4, 338-342.

61. Swapna, I.; SathyaSaiKumar, K.V.; Murthy, R.K.; Dutta-Gupta, A.; Senthilkumaran, B. Changes in cerebral membrane lipid composition and fluidity during thioacetamide-induced hepatic encephalopathy. J. Neurochem. 2006, 98, 1899-1907.

62. Bell, M.; Sikka, S.C.; Rajasekaran, M.; Hellstrom, W. Time course of hydrogen peroxide induced changes in the lipid peroxidation of human sperm membranes. Adv. Contracept. Deliv. Syst. 1992, 8, 144-150.

63. Lenzi, A.; Gandini, L.; Picardo, M.; Tramer, F.; Sandri, G.; Panfili, E. Lipoperoxidation damage of spermatozoa polyunsaturated fatty acids (PUFA): Scavenger mechanisms and possible scavenger therapies. Front. Biosci. 2000, 1, E1-E15.

64. Lerda, D.; Rizzi, R. Study of reproductive function in persons occupationally exposed to 2,4-dichlorophenoxyacetic acid (2,4-D). Mutat. Res. 1991, 262, 47-50.

(C) 2015 by the authors; licensee MDPI, Basel, Switzerland. This article is an open access article distributed under the terms and conditions of the Creative Commons Attribution license (http://creativecommons.org/licenses/by/4.0/). 